This item was submitted to Loughborough's Research Repository by the author.

Items in Figshare are protected by copyright, with all rights reserved, unless otherwise indicated.

\title{
The muscle morphology of elite sprint running
}

\section{PLEASE CITE THE PUBLISHED VERSION}

https://doi.org/10.1249/MSS.0000000000002522

\section{PUBLISHER}

American College of Sports Medicine (ACSM)

\section{VERSION}

AM (Accepted Manuscript)

\section{PUBLISHER STATEMENT}

This paper was accepted for publication in the journal Medicine and Science in Sports and Exercise and the definitive published version is available at https://doi.org/10.1249/MSS.0000000000002522.

\section{LICENCE}

CC BY-NC-ND 4.0

\section{REPOSITORY RECORD}

Miller, Robert, Thomas G Balshaw, Garry J Massey, Sumiaki Maeo, Marcel B Lanza, Michael Johnston, Sam Allen, and Jonathan Folland. 2020. "The Muscle Morphology of Elite Sprint Running". Loughborough University. https://hdl.handle.net/2134/13078007.v1. 
The Muscle Morphology of Elite Sprint Running

Original Investigation

Robert Miller ${ }^{1,2}$, Thomas G. Balshaw ${ }^{1}$, Garry J. Massey ${ }^{3}$, Sumiaki Maeo ${ }^{4}$, Marcel B. Lanza $^{5}$, Michael Johnston ${ }^{2,6}$, Sam J. Allen', Jonathan P. Folland ${ }^{1}$

${ }^{1}$ School of Sport, Exercise and Health Sciences, Loughborough University, UK

${ }^{2}$ British Athletics, Loughborough University, UK

${ }^{3}$ School of Sport and Health Sciences, University of Exeter, Devon, UK

${ }^{4}$ Research Organization of Science and Technology, Ritsumeikan University, Kusatsu, Shiga, Japan

${ }^{5}$ Department of Physical Therapy and Rehabilitation, University of Maryland Baltimore, Baltimore, United States

${ }^{6}$ Applied Sports Technology Exercise and Medicine Research Centre, Swansea University, UK

\section{Address for Correspondence:}

Jonathan P. Folland, Ph.D

School of Sport, Exercise and Health Sciences, Loughborough University, Leicestershire, LE11 3TU, United Kingdom

Tel: +44 (0)1509226334

E-mail: J.P.Folland@lboro.ac.uk

Title Character Count: 45

Abstract word count: 274

Number of figures and tables: 3 figures, 3 tables. 


\section{ABSTRACT}

2 The influence of muscle morphology and strength characteristics on sprint running 3 performance, especially at elite level, is unclear. Purpose: This study aimed to investigate

4 the differences in muscle volumes and strength between male elite sprinters, sub-elite 5 sprinters, and untrained controls; and assess the relationships of muscle volumes and strength

6 with sprint performance. Methods: Five elite sprinters (100 m seasons best [SBE 100$]: 10.10 \pm$ $7 \quad 0.07 \mathrm{~s}), 26$ sub-elite sprinters $\left(\mathrm{SBE}_{100}: 10.80 \pm 0.30 \mathrm{~s}\right)$ and 11 untrained control participants 8 underwent: 3T magnetic resonance imaging scans to determine the volume of 23 individual 9 lower limb muscles/compartments and 5 functional muscle groups; and isometric strength 10 assessment of lower body muscle groups. Results: Total lower body muscularity was distinct 11 between the groups (controls $<$ sub-elite $+20 \%<$ elite $+48 \%$ ). The hip extensors exhibited the 12 largest muscle group differences/relationships (elite, $+32 \%$ absolute and $+15 \%$ relative [per $13 \mathrm{~kg}$ ] volume vs sub-elite; explaining $31-48 \%$ of the variability in $\mathrm{SBE}_{100}$ ), whereas the 14 plantarflexors showed no differences between sprint groups. Individual muscle differences 15 showed pronounced anatomical specificity (elite vs sub-elite, absolute volume range $+57 \%$ to $16-9 \%$ ). Three hip muscles were consistently larger in elite vs. sub-elite (TFL, sartorius, gluteus 17 maximus; absolute $+45-57 \%$ and relative volume $+25-37 \%$ ), and gluteus maximus volume 18 alone explained $34-44 \%$ of the variance in $\mathrm{SBE}_{100}$. Isometric strength of several muscle 19 groups was greater in both sprint groups than controls, but similar for the sprint groups and 20 not related to $\mathrm{SBE}_{100}$. Conclusions: These findings demonstrate the pronounced 21 inhomogeneity and anatomically specific muscularity required for fast sprinting, and provides novel, robust evidence that greater hip extensor and gluteus maximus volumes discriminate between elite and sub-elite sprinters and are strongly associated with sprinting performance.

25 Key Words: Sprinting, muscle volume, isometric strength 
27 Sprint running, including the ability to accelerate quickly and achieve high maximum running speeds, is one of the most revered and long-standing expressions of human athletic performance and is considered a key component of numerous running-based sports. Elite sprinters are capable of achieving impressive gait speeds of over $12 \mathrm{~m} . \mathrm{s}^{-1}$ (1), due to the generation of extremely high muscular power, particularly from the major muscle groups of the lower body. Theoretically, neuromuscular power is largely determined by muscle volume, and empirical evidence has demonstrated very strong relationships between muscle volume and neuromuscular power of single muscle groups (2). This suggests that muscle volume may be of critical importance for sprint performance, and whilst it is a common observation that elite sprinters are typically more muscular than untrained populations, the specific muscle groups important for elite sprint running performance remain unclear.

The 'gold-standard' method of measuring muscle volume is magnetic resonance imaging (MRI; [(3)]), however, to date only a small number of studies have used MRI to investigate the importance of muscle volumes for sprint running performance. Recent evidence supports the notion that sprinters are generally more muscular (i.e. greater muscle volume) than nonsprinters (controls), but with a non-uniform pattern of muscular hypertrophy such that the hip and biarticular hip and knee joint muscles appear to be larger, whereas the monoarticular knee joint muscles and muscles of the lower leg may be more similar $(4,5)$. Moreover, there are also suggestions that the volume of specific muscles could be related to sprint performance, although with considerable confusion about which muscles / muscle groups may be most important; for example there are reports that psoas major (6-8); rectus femoris (4); adductors $(8,9)$; hamstrings $(7,9)$; quadriceps $(8)$, or even ratios of muscle volumes (psoas major:quadriceps [10]; gluteus maximus:quadriceps [7]) may be most important. This 
51 confusion may have arisen as most studies have examined only a limited and variable number of muscles or muscle groups (7-11) rather than a complete analysis of the lower body musculature.

Importantly, comparisons to date have also been limited to sprinters vs. controls $(4,5)$ or sprinters vs. endurance runners (9), rather than what distinguishes elite from sub-elite sprinters. This is because previous studies have not included athletes that are genuinely elite (i.e. internationally competitive) with the fastest personal best $100 \mathrm{~m}$ times of participants being $10.68 \mathrm{~s}$ (11), $10.67 \mathrm{~s}(4), 10.23 \mathrm{~s}$ (7), $10.95 \mathrm{~s}$ (10), division 1 collegiate level sprinters (performance times undefined; [(5)]), and $13.24 \mathrm{~s}$ in preadolescent boys (8). Finally, the number of sprinters assessed has typically been relatively small for quantifying the relationship between sprint performance and muscle volumes $(n=8-16 ;[4,5,8,9,11])$. Thus, no comparison between elite and sub-elite sprinters has yet been made, and the muscle groups that need to be particularly large in order to attain elite running speeds remains to be elucidated.

67 Similarly, the functional characteristics of specific muscle groups needed for elite sprint running remain largely unknown. Whilst some studies have assessed strength, during multiple joint exercises (e.g. squatting, isometric mid-thigh pull) in relation to acceleration and / or sprint performance of athletic groups $(12,13)$, this clearly does not allow identification of which specific muscle groups need to be strong / powerful to enable fast running. Whilst it has been speculated that hip flexion and extension strength may be critical for fast running $(6,7)$, we are aware of only one preliminary study that reported these muscle groups to be stronger in sprinters and largely predictive of sprint performance (14). In fact, to 
76 knee and hip joint muscles in elite and / or sub-elite sprinters as well as untrained controls in

77 order to understand the functional characteristics that may differentiate these groups.

79 Therefore, the aims of this study were to investigate the differences in muscle volumes and 80 strength between elite sprinters, sub-elite sprinters and untrained controls; and to assess the 81 relationships of both muscle volumes and strength with sprint performance amongst sprinters. 82 It was hypothesised that the hip flexor and extensor muscles would be progressively larger 83 relative to body mass according to group (controls $<$ sub-elite $<$ elite), and be related to sprint 84 performance amongst the whole cohort of sprinters. Additionally, it was postulated that 85 isometric torque of the hip flexor and extensor muscle groups would be different between 86 groups, and related to sprint performance. 


\section{METHODS}

\section{Participants \& Sprint Performance}

All of the participants were healthy young men, asymptomatic for leg or back injury, with no minor injury in the previous 4 weeks and no major injury in the previous 6 months. Five elite sprinters (Mean $\pm \mathrm{SD}$; age $27 \pm 4 \mathrm{y}$, body mass $86.4 \pm 6.7 \mathrm{~kg}$, height $1.83 \pm 0.06 \mathrm{~m}$ ), 26 subelite sprinters $(22 \pm 2 \mathrm{y}, 75.4 \pm 7.3 \mathrm{~kg}, 1.78 \pm 0.06 \mathrm{~m})$ and 11 control participants $(26 \pm 3 \mathrm{y}$, $75.2 \pm 5.6 \mathrm{~kg}, 1.80 \pm 0.08 \mathrm{~m}$; Table 1) volunteered to participate and gave informed consent to take part in this study. Elite sprinters were required to have a season's best $100 \mathrm{~m}$ sprint time of $<10.25 \mathrm{~s}$ (the British Athletics $100 \mathrm{~m}$ selection standard for the European Outdoor Championships 2018 [15]). Sub-elite sprinters were required to have a season's best time of 10.35-11.50 s for $100 \mathrm{~m}$ or equivalent for $60 \mathrm{~m} / 200 \mathrm{~m}$ based on International Association of Athletics Federations (IAAF) points, and to have completed at least one season of highintensity sprint-specific training. Participants in both sprint groups completed a minimum of two sprint specific training sessions and one resistance training session per week. Control participants had a low-moderate level of physical activity (i.e. vigorous-intensity activity $\leq 2$ $\mathrm{x}$ per week, and $\leq 1500$ MET-minutes. week $^{-1}$, overall vigorous and moderate physical activity $\leq 3000$ MET-minutes.week $\left.^{-1} ;[(16)]\right)$ and were not involved in systematic physical training or competitive sports (for $\geq 1$ year). Season's best and personal best sprint (60 m, $100 \mathrm{~m}$ and 200 m) times were taken from the national governing body database (www.thepowerof10.info) of electronically timed races with wind readings $\left(<2.0 \mathrm{~m} . \mathrm{s}^{-1}\right)$ during the corresponding calendar year in which data collection took place (season's best); or the athletes career at the end of that season (personal best). Sprint performances were converted to IAAF points, a classification system that allows performance comparisons between different events, and each athletes maximum points in any of the sprint events $(60,100$ and $200 \mathrm{~m})$ was taken as their performance measure and converted back into 100 m season's best equivalent $\left(\mathrm{SBE}_{100}\right)$ 
112 or personal best equivalent $\left(\mathrm{PBE}_{100}\right)$ times. For the elite sprint group $\mathrm{SBE}_{100}(10.10 \pm 0.07$,

113 range $10.03-10.21 \mathrm{~s})$ and $\operatorname{PBE}_{100}(9.99 \pm 0.07$, range 9.91-10.08 s) were actual $100 \mathrm{~m}$

114 performances for all individuals (i.e. $100 \mathrm{~m}$ was their best event). For the sub-elite sprint 115 group $\mathrm{SBE}_{100}$ was actual $100 \mathrm{~m}$ performances for $73 \%$ of these athletes (19 out of 26), whilst

116 for seven athletes $\mathrm{SBE}_{100}$ was derived from either $60 \mathrm{~m}$ or $200 \mathrm{~m}$ season's best times.

117 Consequently, the whole sprint cohort had $\mathrm{SBE}_{100}$ ranging from $10.03-11.50 \mathrm{~s}(10.71 \pm 0.37$

118 s). Ethical approval was granted by the Loughborough University Ethics Approvals (Human

119 Participants) Sub-Committee.

120

121 Study Overview

122 Participants were required to attend two measurement sessions within this cross-sectional 123 study: one for isometric strength measurements and one for assessing muscle morphology 124 (MRI). All measurement sessions were scheduled after a rest day or light training day and 125 participants were instructed to arrive in a relaxed state having followed normal daily activity 126 and dietary behaviours, where they then sat quietly for 15 minutes prior to their MRI scan.

127 Due to limitations in scheduling and practicalities of data collection with elite athletes it was not feasible to control for measurement time of day.

130 Anthropometry

131 Body mass was measured using a calibrated ADAM C-150 weighing scale (ADAM 132 equipment, Oxford, CT), and stature was measured using a wall-mounted stadiometer 133 (Holtain Ltd., Crymmych, UK). Skinfold thickness was measured at eight sites (bicep, tricep, 134 subscapular, iliac crest, supraspinale, abdominal, thigh and calf) using Harpenden skinfold 135 callipers (British Indicators Ltd, Wolverhampton, UK), and the averages of two 136 measurements at each site were recorded. Additionally, waist and gluteal circumferences 
were collected. All anthropometric measures were done by the same investigator, and in

138 accordance with the International Society for the Advancement of Kinanthropometry

139 guidelines (17). The sum of four skinfolds (bicep, tricep, subscapular and iliac crest) was

140 used to calculate body density using the formula for males aged 20-29 years (18), and

141 percentage body fat estimated using the Siri (19) equation. Fat-free mass was derived from

142 the percentage body fat and body mass values.

143

144 Muscle Volume with Magnetic Resonance Imaging

145 T1-weighted axial magnetic resonance (MR) images of the abdomen, thigh and shank were 146 obtained with a 3T scanner (Discovery MR750w, GE Healthcare, Chicago, IL, USA) with a 147 receiver 8-channel whole-body coil. Images (time of repetition $600 \mathrm{~ms}$, time of echo $8 \mathrm{~ms}$, 148 field of view 450 × $450 \mathrm{~mm}$, image matrix 320 × 320, pixel size 1.4 × $1.4 \mathrm{~mm}$, slice thickness

$1495 \mathrm{~mm}$, interslice gap $5 \mathrm{~mm}$ ) were obtained from the twelfth thoracic vertebra to the calcaneus 150 capturing both legs in five overlapping blocks. Subjects were scanned while in the supine 151 position with arms folded across the chest, with hip and knee joints extended and the ankle 152 joint at $\sim 90^{\circ}$. Oil filled capsules were placed in equal segments on the right leg of each 153 participant during scanning, in order to facilitate alignment between the blocks during 154 analysis.

156 The MR images were manually segmented to assess cross-sectional area (CSA) and derive 157 the volume of 23 lower limb muscles / compartments. Specifically, every other MR image 158 (i.e. $20 \mathrm{~mm}$ between the centre of the measured images) starting from the most proximal 159 image in which the muscle appeared, were segmented using a public domain DICOM 160 software (Horos, version 2.2.0 www.thehorosproject.org). The average number of images 161 analysed per muscle is shown in Table 2. Six separate investigators carried out the analysis, 
with each investigator analysing the same muscles / compartments for the entire cohort, and blinded to participant identity / group. Fully analysed images for each participant (i.e. all 26 muscles/compartments) were then checked and quality assured for accuracy by a single investigator (RM), paying particular attention to errors and overlaps between adjacent muscle cross-sections. The analysed muscles / compartments were: iliopsoas (psoas major and iliacus combined); sartorius; tensor fasciae latae (TFL); adductor magnus; gracilis; gluteus maximus; gluteus medius; gluteus minimus; rectus femoris; vastus lateralis, medialis and intermedius; semimembranosus; semitendinosus; biceps femoris long and short heads; popliteus; lateral and medial gastrocnemius; soleus; and the anterior, lateral and deep posterior compartments of the shank. The shank compartments were the combined volume of the following muscles: tibialis anterior, extensor digitorum longus and extensor hallux longus, (anterior); peroneous longus and brevis (lateral); plantaris, tibialis posterior, flexor digitorum longus, flexor hallux longus (deep posterior). The volume of five functional muscle groups were calculated as the sum of the following muscles; hip extensors (gluteus maximus, adductor magnus, biceps

176 femoris long head, semimembranosus and semitendinosus); hip flexors (iliopsoas, rectus

177 femoris, sartorius, TFL); knee extensors (rectus femoris, vastus intermedius, medialis and lateralis); knee flexors (gracilis, biceps femoris long and short head, semimembranosus, semitendinosus, sartorius, popliteus and medial and lateral gastrocnemius); and plantarflexors (medial and lateral gastrocnemius and soleus).

182 The volume of each muscle $\left(\mathrm{V}_{m}\right)$ was calculated using previously outlined methods (7):

$$
V_{m}=\sum_{i=1}^{n-1} \frac{h}{2}\left(A m_{i}+A m_{i+1}\right)
$$


where Am represents the muscle cross sectional area calculated from each image, $i$ is the

187 image number, $n$ is the total number of images, and $h$ is the distance between images (20

$188 \mathrm{~mm})$. In addition to absolute muscle volume $\left(\mathrm{cm}^{3}\right)$, muscle volume was also expressed 189 relative to body mass $\left(\mathrm{cm}^{3} \cdot \mathrm{kg}^{-1}\right)$.

190

Strength Measurements

192 Isometric strength of the five functional muscle groups were assessed with custom-built isometric dynamometers in the following order (for reference hip $\left[180^{\circ}\right]$, knee $\left[180^{\circ}\right]$ and

194 ankle $\left[90^{\circ}\right]$ angles in the anatomical position; flexion is lower): hip extensors (upper body 195 prone, hip $145^{\circ}$, knee $150^{\circ}$ ); hip flexors (upper body supine, hip $180^{\circ}$, knee $150^{\circ}$ ); knee extensors (sitting, hip $115^{\circ}$, knee $120^{\circ}$ ); knee flexors (upper body prone, hip $150^{\circ}$, knee $150^{\circ}$ ); and plantarflexors (sitting, hip $110^{\circ}$ knee $180^{\circ}$, ankle $100^{\circ}$ ). Measurements were made unilaterally, first with the right leg then the left, before moving to the next dynamometer. Participants were tightly secured to each dynamometer using extensive strapping in order to

200 minimise extraneous movement. During extension and flexion of the hip and knee, a 201 calibrated S-shaped strain gauge (linear response up to $2000 \mathrm{~N}$ ) and specific braces were 202 positioned in the movement plane perpendicular to the long axis of femoral / tibial movement and strapped $4 \mathrm{~cm}$ proximal to the knee / ankle joints, respectively. During plantarflexion contractions force data was collected using a portable Kistler force plate (Type 9602A,

205 Kistler Instruments Corp, Winterthur, Switzerland) mounted to a custom-built rig. For all 206 isometric measurements, the force signal was amplified (x500), interfaced with an analogue 207 to digital converter (CED micro 1401, CED, Cambridge, UK) and sampled at $2000 \mathrm{~Hz}$ with a 208 personal computer using Spike 2 software (CED, Cambridge, UK). 
210 With each dynamometer and muscle group, participants first completed a standardised series

211 of warm-up contractions, each of $3 \mathrm{~s}$ duration with $15 \mathrm{~s}$ rest in-between $(3 \times 50 \%, 3 \times 75 \%, 1$

212 x $90 \%$ perceived maximum) followed by at least two subsequent maximal voluntary

213 contractions of the relevant muscle group, lasting $\sim 4 \mathrm{~s}$ with at least $60 \mathrm{~s}$ rest in between. A

214 third contraction was completed if the participant scored higher on their second contraction

215 than the first. During the maximal contractions, participants were given strong verbal

216 encouragement, instructed to push as hard as possible for the duration of the contraction, and

217 were provided with real-time biofeedback displayed on a computer monitor with a target

218 cursor representing their maximum force in preceding contractions. Maximal voluntary force

219 (MVF) was the highest instantaneous force achieved, corrected for the force due to gravity

220 (i.e. baseline force at rest), and maximal voluntary torque (MVT) was calculated as the product of MVF and measured lever length (m). For the hip and the knee muscle groups lever length was manually measured as the distance between the centre of the strap and the centre of rotation of the respective joint. In order to calculate plantarflexion lever length, sagittal plane video was recorded synchronous to the force measurement at $60 \mathrm{~Hz}$ during the MVCs with a camera (Panasonic, HC-V110, Kadoma, Japan) placed $4 \mathrm{~m}$ perpendicular to the movement plane, with the field of view maximised with optical zoom and markers on the knee joint, lateral malleolus and the lateral head of the fifth metatarsal. The corners of the force plate and ankle location were manually digitised and ankle torque was calculated as the perpendicular distance from the normal force vector to the ankle joint centre, multiplied by

230 the magnitude of the normal force vector.

Statistical Analysis

233 Muscle volume and strength measurements assessed on both legs were averaged to provide

234 unilateral criterion values for each participant. Data are presented as mean \pm standard 
235 deviations (SD). The Shapiro-Wilk test was used to assess the normality of distribution, and 236 revealed that $>90 \%$ of the variables were normally distributed, in which case we used

237 parametric statistical tests to provide a consistent approach. One-way ANOVA and 238 subsequent Bonferroni post-hoc analysis were used to assess differences between groups for 239 muscle volume (absolute, and relative to body mass), torque (absolute, and relative to body 240 mass) and anthropometry. Statistical significance was set at $\mathrm{P}<0.05$. For the whole cohort of 241 sprinters (i.e. elite and sub-elite groups combined, not including the control group) the 242 bivariate relationships between $\mathrm{SBE}_{100}$ and measures of muscle volume and strength were 243 assessed using Pearson's product moment correlation. Correlation coefficients were 244 categorised as 'weak' $(\mathrm{r} \leq 0.40)$, 'moderate' $(\mathrm{r}=0.40-0.60)$, 'strong' $(\mathrm{r}=0.60-0.80)$ or 'very 245 strong' $(\mathrm{r}=0.8-1.0)$. Correlation $\mathrm{P}$ values were corrected for multiple tests using the 246 Benjamini-Hochberg (20) method with a false discovery rate of 5\% and the significance level 247 was defined as adjusted $\mathrm{P}<0.05$. Stepwise multiple linear regression was used to calculate the 248 variance in $\mathrm{SBE}_{100}$ explained by the best combination of variables in each of the following 249 categories: absolute and relative muscle volume of individual muscles and muscle groups. In 250 practice based on their significant bivariate correlations with $\mathrm{SBE}_{100}$ the following were entered into four distinct regression analyses for each of these categories of variables: (i)

252 absolute volume of muscle groups (5 muscle groups); (ii) absolute muscle volume of 253 individual muscles (18 specific muscles); (iii) relative volume of muscle groups (2 muscle 254 groups); (iv) relative volume of individual muscles (1 specific muscle). All statistical 255 procedures were performed with IBM SPSS Statistics Version (IBM Corp., New York, N, 256 USA). 


\section{RESULTS}

258

259

260

\section{Anthropometrics}

Elite sprinters were similar in stature, but heavier $(>10 \mathrm{~kg})$ than both sub-elite sprinters and untrained controls $(\mathrm{P}=0.006$ and $\mathrm{P}=0.013$ respectively; Table 1$)$. Both sprint groups had a lower percentage body fat and sum of 8 skinfolds compared with controls $(\mathrm{P} \leq 0.01)$. Fat free mass was greater in elite sprinters than both sub-elite sprinters $(>12 \mathrm{~kg}, \mathrm{P} \leq 0.01)$ and controls $(>16 \mathrm{~kg}, \mathrm{P} \leq 0.01)$.

\section{Comparison of Absolute Muscle Volumes}

Total unilateral volume of all the measured muscles was greater for both sprint groups vs. controls (elite $+48 \%$; sub-elite $+20 \%$; both $\mathrm{P}<0.01$ ) and for the elite vs. sub-elite sprinters (+24\%; $\mathrm{P}=0.01$; Table 2). Elite sprinters had greater absolute muscle volume than sub-elite sprinters for four functional muscle groups (hip extensors $+32 \%$; knee flexors $+24 \%$; hip flexors $+23 \%$; knee extensors $+22 \%$; All $\mathrm{P} \leq 0.01$; Figure 1 ), but not the plantarflexors. Compared to controls, sub-elite sprinters had greater muscle volume of four functional muscle groups $(+20-34 \%, P \leq 0.009$; except the plantarflexors; See Figure, Supplemental Digital Content 1, Percentage differences in absolute and relative muscle volumes between sub-elite sprinters vs. controls). The functional muscle groups and individual muscles are ordered according to the magnitude of the percentage differences for absolute muscle volume), and elite sprinters were larger in all 5 functional muscle groups $(+29-77 \%$, all $\mathrm{P} \leq 0.020)$. When comparing absolute volume of individual muscles / compartments between groups there were non-uniform differences and pronounced anatomical specificity e.g. elite vs sub-elite sprinters ranging from $+57 \%$ (TFL) to $-9 \%$ (lateral compartment of the shank). 
282 Eight individual muscles were larger in elite vs sub-elite sprinters (all $\mathrm{P} \leq 0.035$ ): TFL $283(+57 \%)$, sartorius $(+47 \%)$, gluteus maximus (+45\%), adductor magnus (+28\%), 284 semitendinosis $(+28 \%)$, biceps femoris long head $(+27 \%)$, vastus medialis $(+24 \%)$ and vastus 285 intermedius $(+22 \%)$. Furthermore, compared to controls, elite sprinters had 15 out of 23 286 muscles / compartments that were larger $(+36-106 \%, \mathrm{P} \leq 0.018)$, and sub-elite sprinters had 10 287 muscles / compartments that were larger $(+19-60 \%, \mathrm{P} \leq 0.019)$. In summary, for absolute muscle volumes, similar differences were noted for the two comparisons between sub-elite sprinters vs. controls and elite vs. sub-elite sprinters (See Table, Supplementary Digital Content 2, A summary table of the observed significant differences between sub-elite sprinters vs. controls, and elite sprinters vs. sub-elite sprinters).

\section{Comparison of Relative Muscle Volumes}

296 Regarding relative muscle volume, total volume of the measured muscles was greater for

297 both sprint groups vs. controls (elite $+29 \%, \mathrm{P}<0.001$; sub-elite $+20 \%, \mathrm{P}=0.001$ ), but with no differences between the sprint groups $(\mathrm{P}=0.107)$. The hip extensors were the only muscle group to differentiate elite from sub-elite sprinters based on relative muscle volume $(+15 \%$, $\mathrm{P}=0.003$ ), and the only individual muscles that had larger relative muscle volume in the elite vs. sub-elite sprinters were the gluteus maximus $(+25, \mathrm{P} \leq 0.001)$, sartorius $(+28 \%, \mathrm{P}=0.013)$, and tensor fasciae latae $(+37 \%, \mathrm{P}=0.032)$. Compared to controls, both sprint groups had greater relative muscle volume of the flexors and extensors of the hip and knee (i.e. four muscle groups; $+20-54 \%$, all $\mathrm{P} \leq 0.001$ ), but there were no differences for the plantarflexors. Additionally, in comparison to controls the sprint groups had 13 (elite sprinters, $+24-77 \%$ ) and 12 (sub-elite sprinters, $+16-58 \%$ ) larger individual muscles relative to body mass. In 
summary, for relative muscle volumes, whilst there were many differences between sub-elite sprinters vs. controls, there were far fewer differences between elite vs. sub-elite sprinters (See Table, Supplementary Digital Content 2, A summary table of the observed significant differences between sub-elite sprinters vs. controls, and elite sprinters vs. sub-elite sprinters).

\section{**Insert Figure 1 here**}

\section{Relationships between Sprint Performance and Muscle Volumes}

315 Amongst the whole sprint cohort, $\mathrm{SBE}_{100}$ showed moderate to strong correlations with

316 absolute muscle volume of all the muscles combined ( $\mathrm{r}=-0.629, \mathrm{P}<0.001)$, each of the five muscle groups ( $\mathrm{r}=-0.495$ to $-0.689, \mathrm{P} \leq 0.05$, Table 3 ), as well as 18 out of 23 individual muscles / compartments ( $\mathrm{r}=-0.409$ to -0.662 ; All $\mathrm{P} \leq 0.05)$ i.e. only five individual muscles were not correlated with $\mathrm{SBE}_{100}$. The highest correlations of absolute muscle volumes with $\mathrm{SBE}_{100}$ for any muscle group was the hip extensors $(\mathrm{r}=-0.689, \mathrm{P}<0.001)$ and for any individual muscle was the gluteus maximus ( $\mathrm{r}=-0.639, \mathrm{P}<0.001$; Figure 2$)$. Relative to body mass, the combined volume of all the muscles ( $\mathrm{r}=-0.422, \mathrm{P}=0.036)$, two muscle groups (hip extensors $r=-0.560, \mathrm{P}=0.005$; and knee flexors $\mathrm{r}=-0.522, \mathrm{P}=0.006$ ) and only one individual muscle (gluteus maximus $\mathrm{r}=-0.580, \mathrm{P}=0.014$ ) were moderately associated with $\mathrm{SBE}_{100}$ (Figure 2). Two further individual muscle volumes relative to body mass, however, displayed a tendency to be moderately related to $\mathrm{SBE}_{100}$ (sartorius $\mathrm{r}=-0.484, \mathrm{P}=0.066$; TFL $\mathrm{r}=-0.454$, $\mathrm{P}=0.079)$. The regression models revealed that only the single strongest predictor variable contributed to the explained variance in $\mathrm{SBE}_{100}$ within each category of predictor variables: absolute volume of muscle groups, hip extensors explained $47.5 \%$ of the variance in $\mathrm{SBE}_{100}$;

330 relative volume of muscle groups, hip extensors explained $31.4 \%$ of the variance; absolute 
volume of individual muscles, gluteus maximus explained $43.8 \%$ of the variance, relative volume of individual muscles, gluteus maximus explained $33.6 \%$ of the variance.

\section{**Insert Table 3 and Figure 2 here ${ }^{* *}$}

Isometric Strength

Sub-elite sprinters had greater absolute strength of the knee extensors $(+26 \%, \mathrm{P}=0.001)$ and flexors $(47 \%, \mathrm{P}=0.005)$ compared to controls, but with no differences in any other muscle groups. Elite sprinters showed a distinct pattern of differences compared to controls with greater absolute strength of the hip flexors $(+55 \%, \mathrm{P}=0.002)$ and extensors $(+63 \%, \mathrm{P}=0.002)$, and knee flexors $(+62 \%, \mathrm{P}=0.013$; Figure 3$)$. When relative torque was compared, sub-elite sprinters outperformed controls across all muscle groups (mean difference $+34 \%, \mathrm{P} \leq 0.027$ ) Similar to absolute torque, the elite group produced greater relative torque than the controls during hip extension $(+48 \%, \mathrm{P}=0.002)$, hip flexion $(+40 \%, \mathrm{P}=0.007)$ and knee flexion $(+49 \%, \mathrm{P}=0.049)$ than the controls. However, there were no differences observed in absolute or relative torque between elite and sub-elite sprinters across any of the five muscle groups (Figure 3).

Absolute strength of all five muscle groups was unrelated to sprint performance. For relative strength, counterintuitively one muscle group, relative knee extensor strength, was positively correlated with $\mathrm{SBE}_{100}(\mathrm{r}=0.485, \mathrm{P}=0.033$; i.e. greater knee extension torque, slower sprint time), but there were no relationships for other muscle groups ( $r=-0.265$ to $0.139, \mathrm{P}>0.105)$. 
356 The aim of this study was to compare the lower body muscle volumes and strength

357 characteristics between a group of genuinely elite sprinters with sub-elite sprinters and 358 untrained controls; and to assess the relationships of these measures with sprint performance amongst sprinters. MRI analysis revealed total lower body muscularity was distinct between

360 all three groups (vs. controls: sub-elite $+20 \%$, elite $+48 \%$ ), such that the elite sprinters had $361 \sim 3.7 \mathrm{~kg}$ and $\sim 2.2 \mathrm{~kg}$ of extra muscle mass per leg than controls and sub-elite sprinters respectively. However, the differences in muscle volume between the groups were highly non-uniform with substantial anatomical specificity according to muscle group and especially individual muscle. For elite vs sub-elite sprinters, the largest muscle group specific effects were found primarily for the hip extensors (differences of $+32 \%$ absolute and $+15 \%$ relative volume; explaining $47.5 \%$ [absolute volume] to $31.4 \%$ [relative volume] of the variability in performance) and secondarily for the knee flexors (differences of $+24 \%$ absolute volume; performance correlations for absolute [ $\mathrm{r}=-0.682]$ and relative $[\mathrm{r}=-0.522]$ volume), whereas the plantarflexors showed no differences between the sprint groups. Individual muscles showed even greater anatomical specificity with three muscles being larger in elite vs. subelite sprinters in both absolute and relative terms (TFL, absolute $+57 \%$, relative $+37 \%$; sartorius, absolute, $+47 \%$, relative $+28 \%$; gluteus maximus, absolute $+45 \%$, relative $+25 \%$ ) and the gluteus maximus alone explained $33.6 \%$ (relative volume) to $43.8 \%$ (absolute volume) of the variance in performance amongst sprinters. Whilst both sprint groups had stronger hip and knee muscle groups than controls, isometric strength did not differentiate between sprint groups and was unrelated to sprint performance. Therefore, this study provides novel and robust evidence highlighting the importance of specific morphological characteristics, principally hip extensor and gluteus maximus volume, for elite sprint running. 
380 For the control group in this study, both muscle volume and knee joint muscular strength

381 were comparable to previously published investigations utilising similar measurements in

382 analogous populations (21-23). Both sprint groups demonstrated relatively large muscle

383 volumes when compared with previous studies, however comparison to previous literature is

384 confounded by differences in performance standard, the inclusion of both male and female

385 sprinters in some studies (5) and potential ethnic differences (7). The performance standard

386 of the elite sprinters in this study $\left(\mathrm{n}=5\right.$; $\mathrm{SBE}_{100} 10.03-10.21 \mathrm{~s}$; $\left.\mathrm{PBE}_{100} 9.91-10.08 \mathrm{~s}\right)$ were

387 all faster than any previously studied individual sprinter or cohort (e.g. fastest personal best

$38810.23-11.71 \mathrm{~s}[4,7,9])$. The sub-elite group in the current study (PBE $100: 10.34-11.24 \mathrm{~s})$

389 were of a comparable, if not higher, performance standard to previous research. Hence this

390 appears to be the first comprehensive comparison of muscle morphology and strength between genuinely elite sprinters with sub-elite sprinters and controls.

392

\section{Absolute Muscle Volume}

394 Preliminary anthropometrics revealed the three groups had similar stature and BMI, but both

395 sprint groups were leaner than controls and the elite group were heavier $(>11 \mathrm{~kg})$ and had 396 greater FFM $(>13 \mathrm{~kg})$ than both the other groups. From the MRI analysis, total muscle

397 volume of all the muscles was distinct and progressively larger according to sprint 398 performance (controls < sub-elite $+20 \%<$ elite $+48 \%$ ) with elite sprinters having $\sim 4.4 \mathrm{~kg}$ (vs 399 sub-elite) and $\sim 7.4 \mathrm{~kg}$ (vs controls) of extra muscle mass across both legs. These differences 400 in lower limb muscularity are in accordance with, but more pronounced than, previous 401 studies of sub-elite sprinters $(5,7)$. The mechanistic reason for the greater muscularity of elite $402>$ sub-elite > controls in the current study, are not possible to discern from this investigation, 403 although it seems likely that the sprint and resistance training history of the groups, which 404 shows a similar pattern, would contribute to these differences in muscularity. 
406 Furthermore, there was extensive anatomical variability in the magnitude of differences

407 between muscle groups and particularly individual muscles / compartments. Specifically 408 there were differences between all 3 groups (elite>sub-elite>controls) for 4 out of 5 muscle 409 groups, with the greatest differences in hip extensors (sub-elite $+34 \%$; elite $+77 \%$ vs 410 controls) followed by the knee flexors $(+27 \% ;+58 \%)$, hip flexors $(+27 \% ;+57 \%)$ and knee 411 extensors $(+20 \%$; $+46 \%)$, whereas only the elite sprinters $>$ controls for the plantarflexors $412(+29 \%)$. The broad pattern of these findings, with the largest differences in the hip and knee 413 joint muscles, but less pronounced differences for the ankle joint muscles is in accordance 414 with previous research comparing sub-elite sprinters vs. non-sprinters $(4,5)$. The current study has extended those findings, with elite runners found to have particularly pronounced muscularity of the hip extensors and flexors, and knee flexors, and thus to our knowledge this

417 is the only research study to date highlighting the morphological characteristics important for 418 elite level sprinting. At running speeds $>7.5 \mathrm{~m} \cdot \mathrm{s}^{-1}$ there appears to be a disproportionate 419 requirement for power generation by the hip flexors, hip extensors and knee flexor muscle groups (24). Biomechanically the hip extensors are primarily responsible for the back swing of the legs during stance (25), and both the hip extensor and knee flexors facilitate the application of horizontal forces to the ground (26), and thus these muscle groups are considered critical for propulsion (27). Whereas, the hip flexors are thought crucial to the rapid acceleration of the legs during swing phase in order to achieve high stride frequencies $(24,28)$. From this perspective it is logical that elite sprinters would be larger in these muscle groups.

Individual muscle differences between the groups showed pronounced anatomical specificity with the muscles of elite vs. sub-elite sprinters ranging from $+57 \%$ (TFL) to $-9 \%$ (lateral 
compartment of the shank). Elite sprinters had 8 out of 23 larger muscles / compartments vs.

431 sub-elite (+22-57\%: TFL, sartorius, gluteus maximus, semitendinosus, adductor magnus, biceps femoris long head, vastus intermedius and vastus medialis) and with 6 of these being hip muscles. Furthermore, both sprint groups had 10 (sub-elite $+20-47 \%$ ) and 15 (elite +35 115\%) larger muscles / compartments than controls. Strikingly, amongst the sprinters total muscle volume, the volume of all five muscle groups and 18/23 individual muscles were all found to be related to $\mathrm{SBE}_{100}$ (i.e. greater volume, faster sprint time). However, strong relationships ( $r>0.60$ ), and in fact the highest correlations in this study, were observed between $\mathrm{SBE}_{100}$ and volume of the hip extensor $(\mathrm{r}=-0.689)$ and knee flexor muscle groups $(\mathrm{r}=-0.682)$ as well as two constituent muscles from within these groups (gluteus maximus $\mathrm{r}=$ -0.662 ; and sartorius $\mathrm{r}=-0.639$ ). The largest previous study of muscle morphology in subelite sprinters also reported the absolute volume of 4/12 individual muscles, including the gluteus maximus and hamstrings, to be related to $100 \mathrm{~m}$ time $(\mathrm{r}=0.37-0.42$; $[(7)])$. Inclusion of elite level sprinters in the current investigation and the somewhat higher average performance standard of our cohort (10.71 vs $10.94 \mathrm{~s}$ [(7)] might explain the more pronounced relationships we have found. Subsequently, regression analyses revealed that absolute volume of the hip extensors explained $47.5 \%$, and gluteus maximus $43.8 \%$ of the variance in sprint running performance, respectively. Given the multifactorial nature of sprint running performance, widely considered to depend on an array of anatomical, biomechanical,

449 physiological, technical and psychological variables (29), the apparent importance of these 450 specific muscle morphology characteristics in explaining $>40 \%$ of the variance in performance is remarkable.

453 Overall, these findings highlight the importance of the absolute size of specific muscle 454 groups (primarily the hip extensors and secondarily knee flexors) and muscles (gluteus 
maximus and sartorius) for sprint performance. The consistency of our findings / differences between both sub-elite sprinters vs. controls and elite sprinters vs. sub-elite sprinters for absolute muscle volumes (See Table, Supplemental Digital Content 2, A summary table of the observed significant differences between sub-elite sprinters vs. controls, and elite sprinters vs. sub-elite sprinters), and the most distinct muscle groups / muscles explaining substantial proportions of the variance in sprint performance, reinforces the apparent veracity of these findings. The primary importance of the hip extensors (the largest muscle group differences for both elite vs. sub-elite, $+32 \%$; and sub-elite vs. controls, $+34 \%$; explaining $47.5 \%$ of the variance in $\mathrm{SBE}_{100}$ ) and gluteus maximus (greater for both elite vs. sub-elite, $+45 \%$; and sub-elite vs. controls, $+35 \%$, explaining $43.8 \%$ of the variance in $\mathrm{SBE}_{100}$ ) are original findings. Previous literature have reported contradictory findings for the primary importance of various muscle groups and muscles $(4,6,8-10)$, without highlighting the importance of the hip extensors and gluteus maximus. These investigations typically used smaller numbers of sprinters $(n=8-16)$ of sub-elite sprinters (fastest individual $100 \mathrm{~m}$ personal best $=10.33 \mathrm{~s}$ ), and have performed less comprehensive morphological analyses (i.e. a limited number of lower body muscles). As discussed above, given the key role of the hip extensors and gluteus maximus in propulsion $(25,26)$, it is surprising that until now there has been little empirical evidence to support their importance for sprint running performance.

474 The importance of absolute muscularity would certainly be expected to be beneficial for 475 absolute power production given the strong association of these variables $\left(\mathrm{R}^{2} \sim 0.80\right.$; [2]), but may be surprising given that sprint running has often been considered to depend on power per unit body mass (i.e. relative muscle volume; [30]). However, theoretical analysis has shown that among runners of similar stature, having greater absolute muscle mass is also biologically necessary in order to attain faster sprinting speeds (31). The current experiment 
adds to the data indicating that absolute muscularity, particularly of key muscle groups and

481 individual muscles, is highly important for sprint running performance. Whilst it seems

482 unlikely, an alternative possibility is that the elite sprinters in this study were coincidentally

483 larger and therefore the apparent abundance of differences between groups and associations

484 with sprint performance we have observed for absolute muscle volumes could be an artefact

485 of their coincidentally greater body mass. In this case, relative muscle volume (per $\mathrm{kg}$ )

486 facilitates body mass independent comparisons, without this potential confounding difference

487 in body mass between the groups.

488

489

\section{Relative Muscle Volume}

490 Relative muscle volume was greater for both sprint groups compared to controls for the

491 flexors and extensors of the hip and knee. For individual muscles the differences in relative muscle volume also showed marked anatomical variability / specificity between the three groups (e.g. elite vs. sub-elite, range $+37 \%$ TFL to $-21 \%$ lateral compartment of the shank).

494 Interestingly however only one muscle group (hip extensors; $+15 \%$ ) and three individual 495 muscles (gluteus maximus; $+25 \%$, sartorius; $+28 \%$, TFL; $+37 \%$ ) were larger in the elite vs. 496 sub-elite sprinters. The TFL and the sartorius have been highlighted as having large

497 differences in volume between sprinters and controls (5), but this is the first study where 498 these muscles have been found to be relatively larger in elite vs. sub-elite sprinters Whilst 499 these muscles have received very little attention to date with regards to their influence on 500 sprint performance, both the TFL and sartorius are key contributors to hip flexion (32). In 501 addition, the sartorius is the only simultaneous knee and hip flexor (33), an important combination of actions in changing limb momentum from down and back at the end of 503 stance, to upwards and forwards during swing, and therefore may be important for early 504 swing phase mechanics and thus sprint performance $(5,25)$. 
506 Furthermore, strong relationships were observed between $\mathrm{SBE}_{100}$ and relative muscle volume

507 of the hip extensor $(r=-0.560)$ and knee flexor $(r=-0.522)$ muscle groups, and specifically in

508 only one individual muscle (gluteus maximus $r=-0.580$ ). Consequently, separate regression

509 analyses for muscle groups and individual muscles revealed that the relative volume of the

510 hip extensors explained $31.4 \%$, and gluteus maximus $33.6 \%$ of the variance in sprint

511 performance, respectively. During sprint running the gluteus maximus is activated from late

512 swing phase to mid-stance (26), accelerating the leg underneath the body (34) and making a

513 major contribution to the generation of propulsive forces along with the hamstring muscles

$514(26,35)$. Thus, greater gluteus maximus volume would be expected to facilitate greater

515 propulsion forces, and therefore greater sprinting speeds. It is interesting that the gluteus

516 maximus, the largest individual muscle in the human body, appears to be particularly

517 important for fast running. The biologically expensive process of developing a large gluteus

518 maximus represents a significant evolutionary investment that presumably confers an

519 advantage for survival. It is possible that the role of the gluteus maximus in facilitating

520 humans to run fast explains the evolution of the gluteus maximus as the largest muscle in the 521 human body.

\section{Isometric Strength}

524 The elite sprinters (absolute and relative 3/5 muscle groups [hip extensors and flexors, and

525 knee flexors] and sub-elite sprinters (absolute 2/5 [knee flexors and extensors]; relative 5/5 muscle groups) were stronger than controls. Due to the observed sprint and resistance training history of the sprint groups, and their greater muscle volume, it is unsurprising that both sprint groups were found to be stronger than controls in a number of muscle groups. 
were discriminatory between sprint groups or negatively associated with sprint performance.

531 This contrasts with previous research demonstrating that measures of isokinetic hip flexion strength were related to aspects of sprint performance (14). Furthermore, the speculated importance of hip extension and plantarflexion force during the stance phase $(24,26)$ and hip

534 flexion force during swing phase $(24,28)$ for fast running, might also make the current results

535 surprising. However, task / contraction specificity may be an important factor influencing the association between strength / power of the hip muscles and sprint performance (6). Therefore, the findings of this study could be a consequence of a lack of specificity between the isometric strength measures of the current study and the dynamic nature of sprint running (36). It is acknowledged however, that isometric strength was only measured on one occasion and with no familiarisation, due to the difficulty in recruiting elite level sprinters for even a single assessment session. Whilst the protocol was clearly the same for all three groups, this may have introduced some noise into the data potentially, reducing the likelihood of finding more subtle differences between groups, especially given the small sample size of the elite

544 sprint group $(\mathrm{n}=5)$.

546 No strength measures were found to be related to faster sprint performance, although a

547 counter-intuitive finding was the positive relationship between relative knee extensor strength 548 and $\operatorname{SBE}_{100}(r=0.485$; i.e. the greater the torque, the slower the sprint time $)$. Previous 549 contrary reports include a negative correlation (37) or no relationship (38) between knee 550 extensor strength and sprint performance in team sports players, rather than the elite level and 551 the sub-elite sprinters of the current study. In addition, work by Dorn and colleagues (24) 552 found that the force requirement of the vastii plateaus as running velocity increases past 5 $553 \mathrm{~m} . \mathrm{s}^{-1}$, perhaps suggesting that knee extensor torque is not a particular limitation of fast 554 running. 


\section{Limitations}

557 There are some limitations associated with the present investigation. First, for some of the 558 sub-elite sprinters (7/26) $\mathrm{SBE}_{100}$ was an estimation based on their superior IAAF points at 559 either 60 or $200 \mathrm{~m}$, and as such may have overestimated their $100 \mathrm{~m}$ performance. However,

560 the difference in group sprint performance time as a result of this estimation was trivial, and this method ensured that the best sprint performance for each individual was used consistently. Second, there was a temporal separation between the performance (i.e. $\mathrm{SBE}_{100}$ ) and the laboratory morphology and strength measurements within this study. Whilst this is clearly a potential confounder that might have reduced the strength of the effects we have observed, the continuity of training in the sprint groups would have reduced the likelihood of large differences in muscle volume or strength between the dates of laboratory assessment and sprint performance. Third, it may be argued that the use of isometric force lacks specificity in relation to sprint running (39), where the joint angular velocities can be very high (e.g. knee extension at $\sim 850 \%$ [(1)]). However, the aim of the current study was to accurately assess the isolated strength of five distinct functional muscle groups (i.e. individual joint torques), given the paucity of data on the function, and particularly comparative strength, of these muscle groups in sprinters vs. controls. Isometric measurements are also known to be highly reliable, sensitive and relatively easy to conduct, and also require limited familiarisation time (36), whereas performing these isolated muscle group measurements dynamically, especially at high velocity, in a consistent and reliable manner would be highly challenging. Finally, the cross-sectional nature of this study means that definitive cause and effect relationships remain unknown. However, on the basis of the pronounced differences and relationships we have observed, and the logical rationale for the importance of the muscle groups (hip extensors, knee flexors) and individual muscles 
580 (gluteus maximus) identified, it seems likely that there is a large causal component to these 581 relationships.

582

583

\section{Practical Summary and Implications}

584 The extensive differences in muscle morphology between elite and sub-elite sprinters and the 585 strength of the relationships we have observed have clear implications for coaches and 586 practitioners. Whilst overall muscularity appeared important for performance (All muscles: absolute volume $+24 \%$ for elite vs sub-elite; performance correlations for absolute [r=-0.629] and relative [r=-0.422] volume), this belied the fact that there were highly variable and nonuniform effects for specific muscle groups and muscles. The largest muscle group specific

590 effects were found primarily for the hip extensors (differences of $+32 \%$ absolute and $+15 \%$ 591 relative volume; explaining $47.5 \%$ [absolute volume] to $31.4 \%$ [relative volume] of the variability in performance) and secondarily for the knee flexors (differences of $+24 \%$ absolute volume; performance correlations for absolute [r=-0.682] and relative $[\mathrm{r}=-0.522]$ volume), whereas the plantarflexors showed no differences between the sprint groups. This evidence strongly supports the idea that developing large hip extensors and knee flexors, for example through resistance training, would be valuable for the sprint athlete looking to enhance performance (27).

599 For absolute muscle volumes very similar factors differentiated both sub-elite sprinters from 600 controls as well as elite vs. sub-elite sprinters (e.g. total muscle volume, four muscle groups 601 in the same order of magnitude, and five individual muscles; See Table, Supplemental Digital

602 Content 2, A summary table of the observed significant differences between sub-elite 603 sprinters vs. controls, and elite sprinters vs. sub-elite sprinters), indicating progressive 604 development of these same variables may continuously improve performance up to elite 
605 level. In contrast, for relative volumes, whilst a wide range of factors distinguished sub-elite

606 sprinters from controls, elite sprinters were differentiated by only four variables (volume of

607 the hip extensor muscle group, TFL, sartorius and gluteus maximus) indicating a more

608 targeted development may be needed for elite performance. Moreover, the need for targeted

609 hypertrophy even within muscle groups is emphasised by the individual muscle findings with

610 three muscles being larger in elite vs. sub-elite sprinters in both absolute and relative terms

611 (TFL, absolute $+57 \%$, relative $+37 \%$; sartorius, absolute, $+47 \%$, relative $+28 \%$; gluteus

612 maximus, absolute $+45 \%$, relative $+25 \%$ ) with the gluteus maximus alone explaining $33.6 \%$

613 (relative volume) to $43.8 \%$ (absolute volume) of the variance in performance amongst

614 sprinters. However, our knowledge of the exercises needed to facilitate hypertrophy of these

615 individual muscles (TFL, sartorius, gluteus maximus) is relatively limited. It is also possible

616 given the greater sprint training experience of the elite group in this study that regular,

617 prolonged sprint training may stimulate many of the morphological characteristics we have

618 observed (40).

619

620 Conclusion

621 In conclusion this investigation highlights for the first time the importance of highly

622 inhomogeneous muscularity, with a specific pattern of distribution for elite sprint running

623 performance compared to sub-elite sprinters and controls. Specifically, this experiment

624 revealed for the first time that the hip extensors of elite sprinters were of a greater absolute

625 and relative size and both these measurements were related to performance, such that hip

626 extensor absolute volume explained $47.5 \%$ of the variability in sprint running performance.

627 Individual muscles showed particularly pronounced differences in the muscle distribution of

628 elite sprinters, with three hip muscles (TFL, sartorius and gluteus maximus) consistently

629 larger in absolute and relative terms, and the absolute volume of the gluteus maximus alone 
630 explained $43.8 \%$ of the variance in sprint performance. Based on this novel evidence it is 631 therefore recommended that coaches and athletes be attentive to the development of muscle 632 volume in these specific lower body muscles to enhance sprint running performance. 
633 Acknowledgements

634 This investigation was financially supported by UK Athletics and the UK Strength and

635 Conditioning Association. The authors would like to thank the participants who gave up their

636 time to take part in this research study, Dr. Bill Haug for his help with data analysis, and Mr.

637 Sam Power for his significant contribution and support in data acquisition.

638

639 Conflicts of Interest

640 No conflicts of interest are relevant to this article. The present results do not constitute

641 endorsement by the American College of Sports Medicine, and the authors declare that the

642 results of the study are presented clearly, honestly and without fabrication, falsification, or 643 inappropriate data manipulation. 


\section{REFERENCES}

645 1. Čoh M, Hébert-Losier K, Štuhec S, Babić V, Supej M. Kinematics of Usain Bolt's 646 maximal sprint velocity. Kinesiology. 2018;50(2):172-80.

647 2. O'Brien TD, Reeves ND, Baltzopoulos V, Jones DA, Maganaris CN. Strong 648 relationships exist between muscle volume, joint power and whole-body external 649 mechanical power in adults and children. Exp. Physiol. 2009;94(6):731-8.

650 3. Cruz-Jentoft AJ, Bahat G, Bauer J et al. Sarcopenia: revised European consensus on 651 definition and diagnosis. Age Ageing. 2019;48(1):16-31.

652

4. Ema R, Sakaguchi M, Kawakami Y. Thigh and Psoas Major Muscularity and Its Relation to Running Mechanics in Sprinters. Med. Sci. Sports Exerc. 2018:2085-91.

5. Handsfield GG, Knaus KR, Fiorentino NM, Meyer CH, Hart JM, Blemker SS. Adding muscle where you need it: non-uniform hypertrophy patterns in elite sprinters. Scand. J. Med. Sci. Sports. 2016:1-11.

6. Copaver K, Hertogh C, Hue O. The effects of psoas major and lumbar lordosis on hip flexion and sprint performance. Res. Q. Exerc. Sport. 2012;83(2):160-7.

7. Sugisaki N, Kobayashi K, Tsuchie H, Kanehisa H. Associations Between Individual Lower Limb Muscle Volumes and 100-m Sprint Time in Male Sprinters. Int. J. Sports Physiol. Perform. 2017:1-19.

662

8. Tottori N, Suga T, Miyake Y et al. Hip Flexor and Knee Extensor Muscularity Are Associated With Sprint Performance in Sprint-Trained Preadolescent Boys. Pediatr. Exerc. Sci. 2018;30(1):115-23.

665 9. Sugisaki N, Kanehisa H, Tauchi K, Okazaki S, Iso S, Okada J. The Relationship 666 between 30-m Sprint Running Time and Muscle Cross-sectional Areas of the Psoas Major and Lower Limb Muscles in Male College Short and Middle Distance Runners. Int J Sports Health Sci. 2011;9:1-7. 
669 10. Hoshikawa Y, Muramatsu M, Iida T et al. Influence of the psoas major and thigh

670

671

672

673

674

675

676

677

678

679

680

681

682

683

684

685

686

687

688

689

690

691

692

693 muscularity on 100-m times in junior sprinters. Med. Sci. Sports Exerc. 2006;38(12):2138-43.

11. Bex T, Iannaccone F, Stautemas $\mathrm{J}$ et al. Discriminant musculo-skeletal leg characteristics between sprint and endurance elite Caucasian runners. Scand. J. Med. Sci. Sports. 2017;27(3):275-81.

12. Chelly MS, Cherif N, Amar MB et al. Relationships of Peak Leg Power, 1 Maximal Repetition Half Back Squat, and Leg Muscle Volume to 5-m Sprint Performance of Junior Soccer Players. J. Strength Cond. Res. 2010;24(1):266-71.

13. Wang R, Hoffman JR, Tanigawa S et al. Isometric Mid-Thigh Pull Correlates with Strength, Sprint and Agility Performance in Collegiate Rugby Union Players. $J$. Strength Cond. Res. 2016;30(11):3051-6.

14. Blazevich AJ, Jenkins DG. Predicting Sprint Running Times from Isokinetic and Squat Lift Tests: A Regression Analysis. J. Strength Cond. Res. 1998;12(2):101-3.

15. UK Athletics 2018 Selection Policies. [Internet]. Available from: https://www.uka.org.uk/performance/2018-selection-policies/.

16. Janczewska L, Lebiedziński B, Stupnicki R, Biernat E. Assessment of physical activity by applying IPAQ questionnaire. Phys Educ Sport. 2008;52(-1):46-52.

17. Eston R, Hawes M, Martin AD, Reilly T. Kinanthropometry and Exercise Physiology Labratory Manual Volume 1: Anthropometry. 3rd ed.: Routledge; 2009. p. 4-53.

18. Durnin JVGA, Womersley J. Body fat assessed from total body density and its estimation from skinfold thickness: measurements on 481 men and women aged from 16 to 72 Years. Br. J. Nutr. 2007;32(01):77-97.

19. Siri WE. The gross composition of the body. In: CA Tobias, JH Lawrence editors. Advances in Biol and Med Phys. New York: Academic Press; 1956, pp. 239-80. 
694 20. Benjamini Y, Hochberg Y. Controlling the False Discovery Rate: A Practical and Powerful Approach to Multiple Testing. J R Stat Soc Series B Stat Methodol.

696 1995;57(1):289-300.

697

21. Evangelidis PE, Massey GJ, Pain MT, Folland JP. Strength and size relationships of the quadriceps and hamstrings with special reference to reciprocal muscle balance. Eur. J. Appl. Physiol. 2016;116(3):593-600.

22. Massey GJ, Balshaw TG, Maden-Wilkinson TM, Tillin NA, Folland JP. Tendinous Tissue Adaptation to Explosive- vs. Sustained-Contraction Strength Training. Front. Physiol. 2018;9:1170.

23. Handsfield GG, Meyer CH, Hart JM, Abel MF, Blemker SS. Relationships of 35 lower limb muscles to height and body mass quantified using MRI. J. Biomech. 2014;47(3):631-8.

706

24. Dorn TW, Schache AG, Pandy MG. Muscular strategy shift in human running: dependence of running speed on hip and ankle muscle performance. J. Exp. Biol.

25. Wiemann K, Tidow G. Relative activity of hip and knee extensors in sprinting implications for training. New Stud Ath. 1995;10:29-49.

26. Morin JB, Gimenez P, Edouard P et al. Sprint Acceleration Mechanics: The Major Role of Hamstrings in Horizontal Force Production. Front. Physiol. 2015;6:404.

27. Delecluse C. Influence of Strength Training on Sprint Running Performance. Current Findings and Implications for Training. Sports Med. 1997;24(3):147-56.

28. Schache AG, Blanch PD, Dorn TW, Brown NAT, Rosemond D, Pandy MG. Effect of 71. 
29. Majumdar AS, Robergs RA. The Science of Speed: Determinants of Performance in the 100 m Sprint. Int J Sports Sci Coa. 2011;6(3):479-93.

30. Morin JB, Edouard P, Samozino P. New Insights into Sprint Biomechanics and Determinants of Elite 100m Performance. New Stud Ath. 2013;3(4):87-103.

31. Weyand PG, Davis JA. Running performance has a structural basis. J. Exp. Biol. 2005;208(Pt 14):2625-31.

32. Andersson EA, Nilsson J, Thorstensson A. Intramuscular EMG from the hip flexor muscles during human locomotion. Acta Physiol. Scand. 1997;161:361-70.

33. Evangelidis PE, Massey GJ, Ferguson RA, Wheeler PC, Pain MTG, Folland JP. The functional significance of hamstrings composition: is it really a "fast" muscle group? Scand. J. Med. Sci. Sports. 2017;27(11):1181-9.

34. Schache AG, Dorn TW, Williams GP, Brown NA, Pandy MG. Lower-limb muscular strategies for increasing running speed. J. Orthop. Sports Phys. Ther. 2014;44(10):813-24.

35. Belli A, Kyr olainen H, Komi PV. Moment and Power of Lower Limb Joints in Running. Int. J. Sports Med. 2002;23:136-41.

36. Wilson GJ, Murphy AJ. The Use of Isometric Tests of Muscular Function in Athletic Assessment. Sports Med. 1996;22(1):19-37.

37. Newman MA, Tarpenning KM, Marino FE. Relationships Between Isokinetic Knee Strength, Single-Sprint Performance, and Repeated-Sprint Ability in Football Players. J. Strength Cond. Res. 2004;18(4):867-72.

38. Cronin JB, Hansen KT. Strength and Power Predictors of Sports Speed. J. Strength Cond. Res. 2005;19(2):349-57. 
741 39. Baker D, Wilson G, Carlyon R. Generality versus specificity: a comparison of dynamic and isometric measures of strength and speed-strength. Eur. J. Appl. Physiol. 1994;68:350-5.

744 40. Nuell S, Illera-Dominguez VR, Carmona G et al. Hypertrophic muscle changes and sprint performance enhancement during a sprint-based training macrocycle in national-level sprinters. Eur J Sport Sci. 2019:1-10. 
Table 1. Performance and training status, and anthropometric characteristics of elite sprinters $(n=5)$, sub-elite sprinters $(n=26)$ and untrained controls ( $n=11)$. Data are presented as mean \pm SD .

\begin{tabular}{|c|c|c|c|c|c|}
\hline & \multirow{2}{*}{$\begin{array}{c}\text { Controls } \\
\text { Mean } \pm \text { SD }\end{array}$} & \multicolumn{2}{|c|}{ Sub-Elite Sprinters } & \multicolumn{2}{|c|}{ Elite Sprinters } \\
\hline & & Mean \pm SD & Range & Mean \pm SD & Range \\
\hline \multicolumn{6}{|l|}{ Performance \& Training Status } \\
\hline $\mathrm{SBE}_{100}(\mathrm{~s})$ & - & $10.80 \pm 0.30$ & $10.36-11.50$ & $10.10 \pm 0.07 * *$ & $10.03-10.21$ \\
\hline $\operatorname{PBE}_{100}(\mathrm{~s})$ & - & $10.69 \pm 0.26$ & $10.34-11.25$ & $9.99 \pm 0.07 * *$ & 9.91-10.08 \\
\hline Sprint Training Duration (Yrs) & - & $5.3 \pm 2.6$ & & $9.2 \pm 3.4 * *$ & \\
\hline Resistance Training Duration (Yrs) & - & $3.5 \pm 2.0$ & & $8.1 \pm 2.6 * *$ & \\
\hline Activity Level (MET-min.week ${ }^{-1}$ ) & $2006 \pm 825$ & & & & \\
\hline \multicolumn{6}{|l|}{ Anthropometrics } \\
\hline Age (yrs) & $25.8 \pm 2.6$ & $22.0 \pm 2.2 \dagger$ & & $27.4 \pm 4.1 * *$ & \\
\hline Height (m) & $1.80 \pm 0.08$ & $1.78 \pm 0.06$ & & $1.83 \pm 0.06$ & \\
\hline Body Mass (kg) & $75.2 \pm 5.6$ & $75.4 \pm 7.3$ & & $86.4 \pm 6.7 * *, \dagger$ & \\
\hline Body Mass Index $\left(\mathrm{kg} \cdot \mathrm{m}^{-2}\right)$ & $23.3 \pm 1.8$ & $24.3 \pm 2.4$ & & $25.0 \pm 1.0$ & \\
\hline Sum of 8 Skinfold (mm) & $88 \pm 32$ & $53 \pm 14 \dagger$ & & $39 \pm 4^{\dagger \dagger}$ & \\
\hline Body Fat Percentage (\%) & $15.5 \pm 4.3$ & $11.2 \pm 3.1 \dagger$ & & $8.3 \pm 1.2^{\dagger}$ & \\
\hline Fat Free Mass (kg) & $63.5 \pm 4.7$ & $67.0 \pm 6.7$ & & $79.8 \pm 6.1 * *, \dagger$ & \\
\hline Waist:Glute Ratio (-) & $0.81 \pm 0.02$ & $0.82 \pm 0.04$ & & $0.84 \pm 0.05$ & \\
\hline
\end{tabular}

Significantly different to sub-elite: ${ }^{*} \mathrm{P} \leq 0.05$ and ${ }^{* *} \mathrm{P} \leq 0.01$, Significantly different to controls: ${ }^{\dagger} \mathrm{P} \leq 0.05$ and ${ }^{\dagger \dagger} \mathrm{P} \leq 0.01$. 
Table 2. Absolute and relative muscle volume of all muscles, five functional muscle groups and 23 individual muscles / compartments of elite sprinters ( $\mathrm{n}=5$ ), sub-elite sprinters $(n=26)$ and untrained controls $(n=11)$. Number of axial images / slices used to assess the volume of each muscle were averaged across all participants. Muscle volume data are presented as group mean $\pm \mathrm{SD}$, with individual measurements the average of both sides/legs (i.e. unilateral).

\begin{tabular}{|c|c|c|c|c|c|c|c|}
\hline \multirow{3}{*}{$\begin{array}{l}\text { Muscle Group / Muscle } \\
\text { or Compartment }\end{array}$} & \multirow{3}{*}{$\begin{array}{l}\text { No. of } \\
\text { Slices }\end{array}$} & \multicolumn{3}{|c|}{ Absolute Muscle Volume $\left(\mathrm{cm}^{3}\right)$} & \multicolumn{3}{|c|}{ Relative Muscle Volume $\left(\mathrm{cm}^{3} \cdot \mathrm{kg}^{-1}\right)$} \\
\hline & & Control & Sub-Elite & Elite & Control & Sub-Elite & Elite \\
\hline & & Group & Sprinters & Sprinters & Group & Sprinters & Sprinters \\
\hline All Muscles & & $7628 \pm 1548$ & $9164 \pm 1207^{\dagger \dagger}$ & $11323 \pm 1328 * *, \dagger$ & $101.42 \pm 7.55$ & $121.51 \pm 10.05^{\dagger \dagger}$ & $131.26 \pm 6.76^{\dagger}$ \\
\hline Hip Flexors & & $1031 \pm 151$ & $1314 \pm 216^{\dagger}$ & $1620 \pm 200 * *, \dagger$ & $13.75 \pm 2.16$ & $17.42 \pm 2.27$ & $18.82 \pm 1.83 \dagger$ \\
\hline Hip Extensors & & $2257 \pm 220$ & $3029 \pm 422 \dagger$ & $4002 \pm 489 * *, \dagger$ & $30.10 \pm 3.14$ & $40.16 \pm 3.77$ & $46.39 \pm 2.88 * *, \dagger \dagger$ \\
\hline Knee Flexors & & $1460 \pm 196$ & $1859 \pm 301 \dagger$ & $2304 \pm 178 * *, \dagger$ & $19.45 \pm 2.72$ & $24.61 \pm 2.79 \dagger$ & $26.78 \pm 0.76^{\dagger \dagger}$ \\
\hline Knee Extensors & & $2202 \pm 315$ & $2636 \pm 401 \pitchfork$ & $3218 \pm 400 * *, \dagger$ & $29.21 \pm 3.09$ & $35.00 \pm 4.36^{\dagger \dagger}$ & $37.31 \pm 2.48^{\dagger \dagger}$ \\
\hline Plantarflexors & & $860 \pm 172$ & $943 \pm 156$ & $1112 \pm 181^{\dagger}$ & $11.39 \pm 1.92$ & $12.48 \pm 1.40$ & $12.92 \pm 1.78$ \\
\hline Iliopsoas & 18 & $514 \pm 75$ & $618 \pm 101^{\dagger}$ & $702 \pm 97 \dagger$ & $6.84 \pm 1.03$ & $8.18 \pm 0.977^{\dagger \dagger}$ & $8.18 \pm 1.10$ \\
\hline Sartorius & 28 & $142 \pm 25$ & $209 \pm 50 \pitchfork$ & $306 \pm 46 * *, \dagger$ & $1.89 \pm 0.28$ & $2.77 \pm 0.62 \pitchfork$ & $3.56 \pm 0.40 *, \dagger$ \\
\hline Tensor Fasciae Latae & 15 & $73 \pm 24$ & $86 \pm 25$ & $135 \pm 41 * *, \dagger$ & $0.97 \pm 0.36$ & $1.14 \pm 0.29$ & $1.56 \pm 0.39 *, \dagger$ \\
\hline Adductor Magnus & 16 & $624 \pm 81$ & $828 \pm 128^{\dagger \dagger}$ & $1056 \pm 83 * *, \dagger$ & $8.30 \pm 0.88$ & $10.99 \pm 1.46^{\dagger \dagger}$ & $12.31 \pm 1.05^{\dagger \dagger}$ \\
\hline Gracilis & 17 & $98 \pm 23$ & $142 \pm 37^{\dagger \dagger}$ & $180 \pm 37^{\dagger \dagger}$ & $1.31 \pm 0.30$ & $1.89 \pm 0.45^{\dagger \dagger}$ & $2.10 \pm 0.39 \dagger$ \\
\hline Gluteus Maximus & 16 & $931 \pm 108$ & $1257 \pm 197$ & $1797 \pm 376 * *, \dagger$ & $12.40 \pm 1.39$ & $16.65 \pm 1.82^{\dagger}$ & $20.75 \pm 3.15 * *, \dagger$ \\
\hline Gluteus Medius & 10 & $384 \pm 49$ & $405 \pm 69$ & $434 \pm 92$ & $5.11 \pm 0.51$ & $5.38 \pm 0.75$ & $5.01 \pm 0.75$ \\
\hline Gluteus Minimus & 9 & $199 \pm 39$ & $170 \pm 36$ & $192 \pm 46$ & $2.66 \pm 0.58$ & $2.25 \pm 0.44$ & $2.22 \pm 0.48$ \\
\hline Rectus Femoris & 21 & $303 \pm 55$ & $401 \pm 78^{\dagger}$ & $476 \pm 45^{\dagger \dagger}$ & $4.05 \pm 0.81$ & $5.33 \pm 0.98 \dagger$ & $5.53 \pm 0.38^{\dagger}$ \\
\hline
\end{tabular}




\begin{tabular}{|c|c|c|c|c|c|c|c|}
\hline Vastus Lateralis & 22 & $743 \pm 98$ & $925 \pm 156^{\dagger \dagger}$ & $1132 \pm 180^{\dagger}$ & $9.88 \pm 1.20$ & $12.26 \pm 1.65^{\dagger \dagger}$ & $13.07 \pm 1.09^{\dagger \dagger}$ \\
\hline Vastus Intermedius & 23 & $680 \pm 115$ & $789 \pm 140$ & $962 \pm 145 *, \dagger$ & $9.01 \pm 1.20$ & $10.48 \pm 1.63 \dagger$ & $11.17 \pm 1.33^{\dagger}$ \\
\hline Vastus Medialis & 19 & $476 \pm 111$ & $521 \pm 79$ & $649 \pm 97 *, \dagger$ & $6.28 \pm 1.11$ & $6.92 \pm 0.89$ & $7.53 \pm 0.89$ \\
\hline Semimembranosus & 17 & $262 \pm 18$ & $327 \pm 59 \dagger$ & $359 \pm 60 \dagger$ & $3.50 \pm 0.33$ & $4.34 \pm 0.63 \dagger$ & $4.16 \pm 0.56$ \\
\hline Semitendinosus & 15 & $219 \pm 39$ & $350 \pm 79 \dagger$ & $449 \pm 70 *$ & $2.93 \pm 0.64$ & $4.63 \pm 0.86^{\dagger \dagger}$ & $5.20 \pm 0.54 \dagger$ \\
\hline Biceps Femoris Long Head & 18 & $221 \pm 42$ & $267 \pm 47^{\dagger}$ & $340 \pm 31 * *, \dagger$ & $2.97 \pm 0.71$ & $3.55 \pm 0.54^{\dagger}$ & $3.96 \pm 0.32 \dagger$ \\
\hline Biceps Femoris Short Head & 7 & $110 \pm 28$ & $131 \pm 34$ & $167 \pm 26 \dagger$ & $1.46 \pm 0.36$ & $1.73 \pm 0.39$ & $1.94 \pm 0.29$ \\
\hline Popliteus & 16 & $19 \pm 6$ & $17 \pm 5$ & $23 \pm 5$ & $0.26 \pm 0.06$ & $0.22 \pm 0.07$ & $0.27 \pm 0.05$ \\
\hline Lateral Gastrocnemius & 13 & $156 \pm 41$ & $170 \pm 37$ & $202 \pm 34$ & $2.06 \pm 0.47$ & $2.25 \pm 0.38$ & $2.36 \pm 0.51$ \\
\hline Medial Gastrocnemius & 14 & $251 \pm 52$ & $262 \pm 58$ & $300 \pm 38$ & $3.33 \pm 0.62$ & $3.50 \pm 0.42$ & $3.50 \pm 0.42$ \\
\hline Soleus & 22 & $453 \pm 95$ & $510 \pm 76$ & $610 \pm 137^{\dagger \dagger}$ & $6.00 \pm 1.08$ & $6.77 \pm 0.76$ & $7.05 \pm 1.25$ \\
\hline Anterior Compartment & 20 & $291 \pm 47$ & $273 \pm 47$ & $302 \pm 59$ & $3.87 \pm 0.53$ & $3.62 \pm 0.52$ & $3.48 \pm 0.46$ \\
\hline Lateral Compartment & 21 & $153 \pm 35$ & $161 \pm 42$ & $147 \pm 32$ & $2.02 \pm 0.39$ & $2.13 \pm 0.46$ & $1.69 \pm 0.27$ \\
\hline Posterior Compartment & 20 & $326 \pm 93$ & $345 \pm 71$ & $401 \pm 76$ & $4.32 \pm 1.12$ & $4.57 \pm 0.82$ & $4.63 \pm 0.60$ \\
\hline
\end{tabular}

Significantly different to sub-elite: ${ }^{*} \mathrm{P} \leq 0.05$ and ${ }^{* *} \mathrm{P} \leq 0.01$, Significantly different to controls: ${ }^{\dagger} \mathrm{P} \leq 0.05$ and ${ }^{\dagger \dagger} \mathrm{P} \leq 0.01$.

All muscles is the sum of muscle volumes from all the muscles/compartments listed. 
1 Table 3. Pearson's product moment correlation coefficients between Seasons Best Equivalent $100 \mathrm{~m}$ $2 \quad\left(\mathrm{SBE}_{100}\right)$ and absolute and relative muscle volume of all muscles, five functional muscle groups and 323 individual muscles in the whole cohort of sprinters $(n=31)$.

Muscle Group / Muscle Absolute Muscle Volume Relative Muscle Volume

All Muscles $\left(\mathrm{cm}^{3}\right)$ $\left(\mathrm{cm}^{3} \cdot \mathrm{kg}^{-1}\right)$

Hip Flexors

$-0.629 * *$

$-0.422 *$

Hip Extensors

$-0.563 * *$

$-0.299$

Knee Flexors

$-0.689 * * *$

$-0.560 * *$

Knee Extensors

$-0.682 * * *$

$-0.522 * *$

Plantarflexors

$-0.495 * *$

$-0.178$

$-0.537 * *$

$-0.309$

Iliopsoas

$-0.442 *$

$-0.120$

Sartorius

$-0.639 * * *$

$-0.484$

Tensor Fasciae Latae

$-0.547 * *$

$-0.454$

Adductor Magnus

$-0.582 * *$

$-0.289$

Gracilis

$-0.564 * *$

$-0.377$

Gluteus Maximus

$-0.662 * * *$

$-0.580 *$

Gluteus Medius

$-0.227$

0.152

Gluteus Minimus

$-0.254$

0.040

Rectus Femoris

$-0.409 *$

$-0.090$

Vastus Lateralis

$-0.475 *$

$-0.199$

Vastus Intermedius

$-0.443 *$

$-0.154$

Vastus Medialis

$-0.431 *$

$-0.114$

Semimembranosus

$-0.478 *$

$-0.194$

Semitendinosus

$-0.530 * *$

$-0.342$

Biceps Femoris Long Head

$-0.475 *$

$-0.190$

Biceps Femoris Short Head

$-0.511 *$

$-0.341$

Popliteus

$-0.435 *$

$-0.260$

Lateral Gastrocnemius

$-0.578 * *$

$-0.398$

Medial Gastrocnemius

$-0.437 *$

$-0.230$

Soleus

$-0.474 *$

$-0.196$

Anterior Compartment

$-0.272$

0.092

Lateral Compartment

$-0.192$

0.045

Posterior Compartment

$-0.290$

0.014

Significant correlations: $* \mathrm{P} \leq 0.05$; $* * \mathrm{P} \leq 0.01$; and $* * * \mathrm{P} \leq 0.001$ following correction for multiple comparisons. 


\section{FIGURE CAPTIONS}

5 Figure 1. Percentage differences in absolute and relative muscle volumes of all muscles, five

6 functional muscle groups and 23 muscles / compartments between elite ( $n=5)$ vs. sub-elite

$7 \quad(n=26)$ sprinters. A positive value indicates greater volume of elite sprinters. The functional

8 muscle groups and individual muscles are ordered according to the magnitude of the

9 percentage differences for absolute muscle volume.

10

11 Figure 2. The relationships between Seasons Best Equivalent $100 \mathrm{~m}\left(\mathrm{SBE}_{100}\right)$ and (A)

12 Absolute hip extensor volume; (B) Relative hip extensor volume; (C) Absolute gluteus

13 maximus volume; (D) Relative gluteus maximus volume. Significant correlations: * $\mathrm{P} \leq 0.05$;

$14 * * \mathrm{P} \leq 0.01$; and $* * * \mathrm{P} \leq 0.001$ following correction for multiple comparisons.

15

16 Figure 3. Comparison of absolute and relative isometric maximum voluntary torque of 5

17 functional muscle groups between elite $(n=5)$ vs sub-elite $(n=26)$ sprinters vs untrained

18 controls $(n=11)$. Data are presented as group mean $\pm S D$, with individual measurements the

19 average of both legs. Significantly different to controls: * $\mathrm{P} \leq 0.05$ and ${ }^{* *} \mathrm{P} \leq 0.01$. 
[Fig. 1]
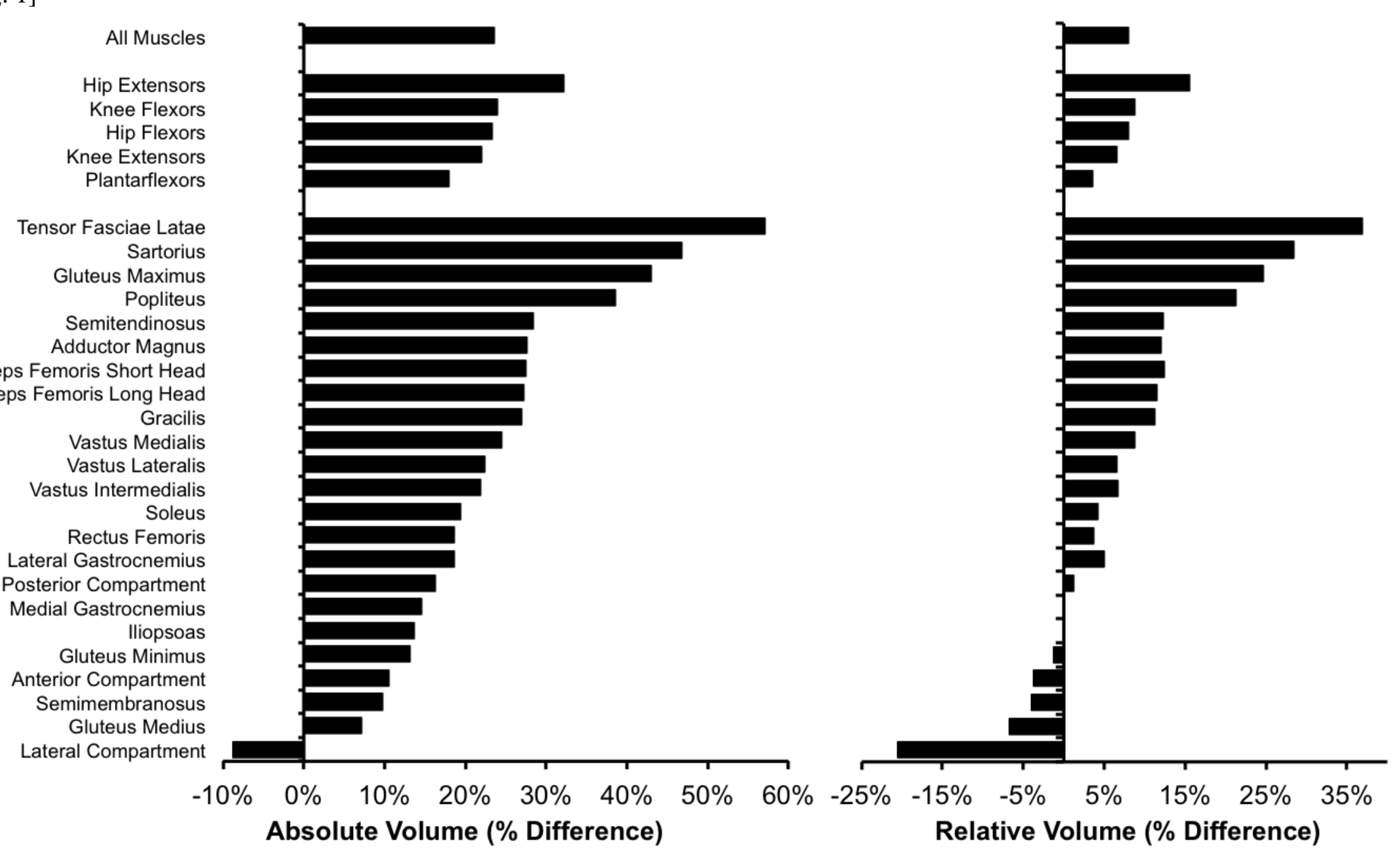

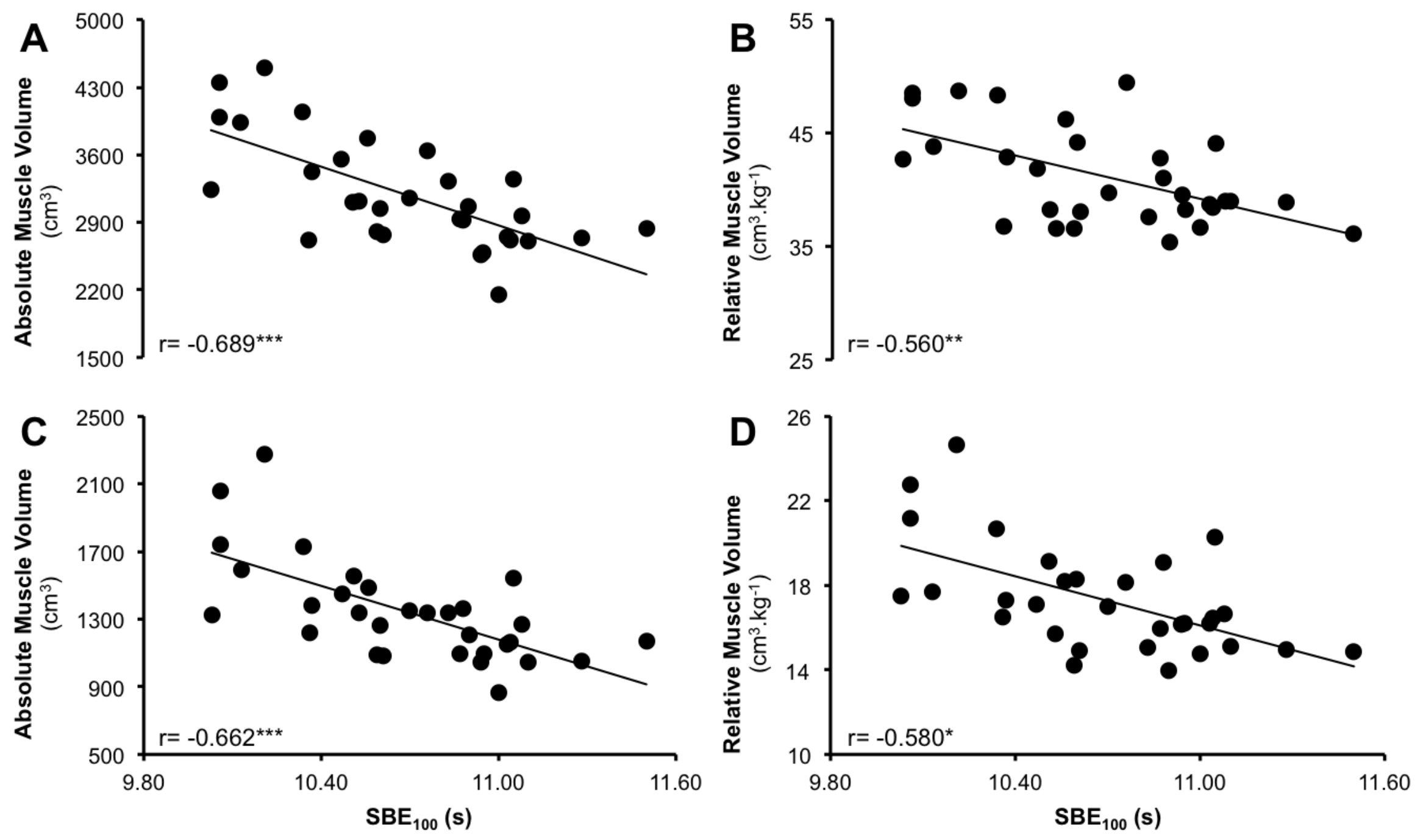
[Fig. 3]

27

28
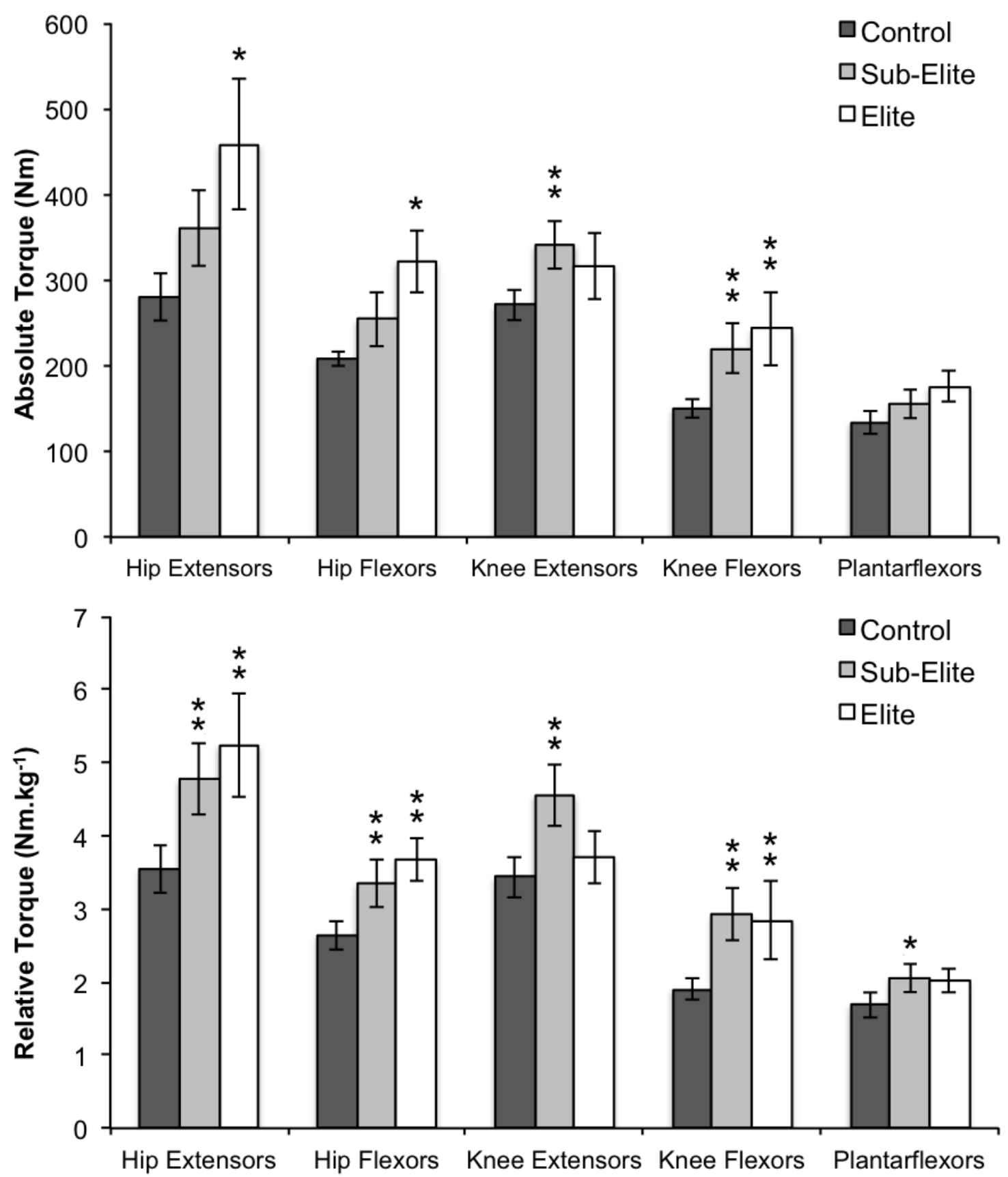
33 Supplemental Digital Content 1. Percentage differences in absolute and relative muscle

34 volumes of all muscles, five functional muscle groups and 23 muscles / compartments 35 between sub-elite sprinters $(n=26)$ vs. controls $(n=11)$. A positive value indicates greater 36 volume of sub-elite sprinters. The functional muscle groups and individual muscles are 37 ordered according to the magnitude of the percentage differences for absolute muscle 38 volume. TIFF

39

40 Supplemental Digital Content 2. A summary table of the observed significant differences 41 between sub-elite sprinters vs. controls, and elite sprinters vs. sub-elite sprinters. Docx 42 43 


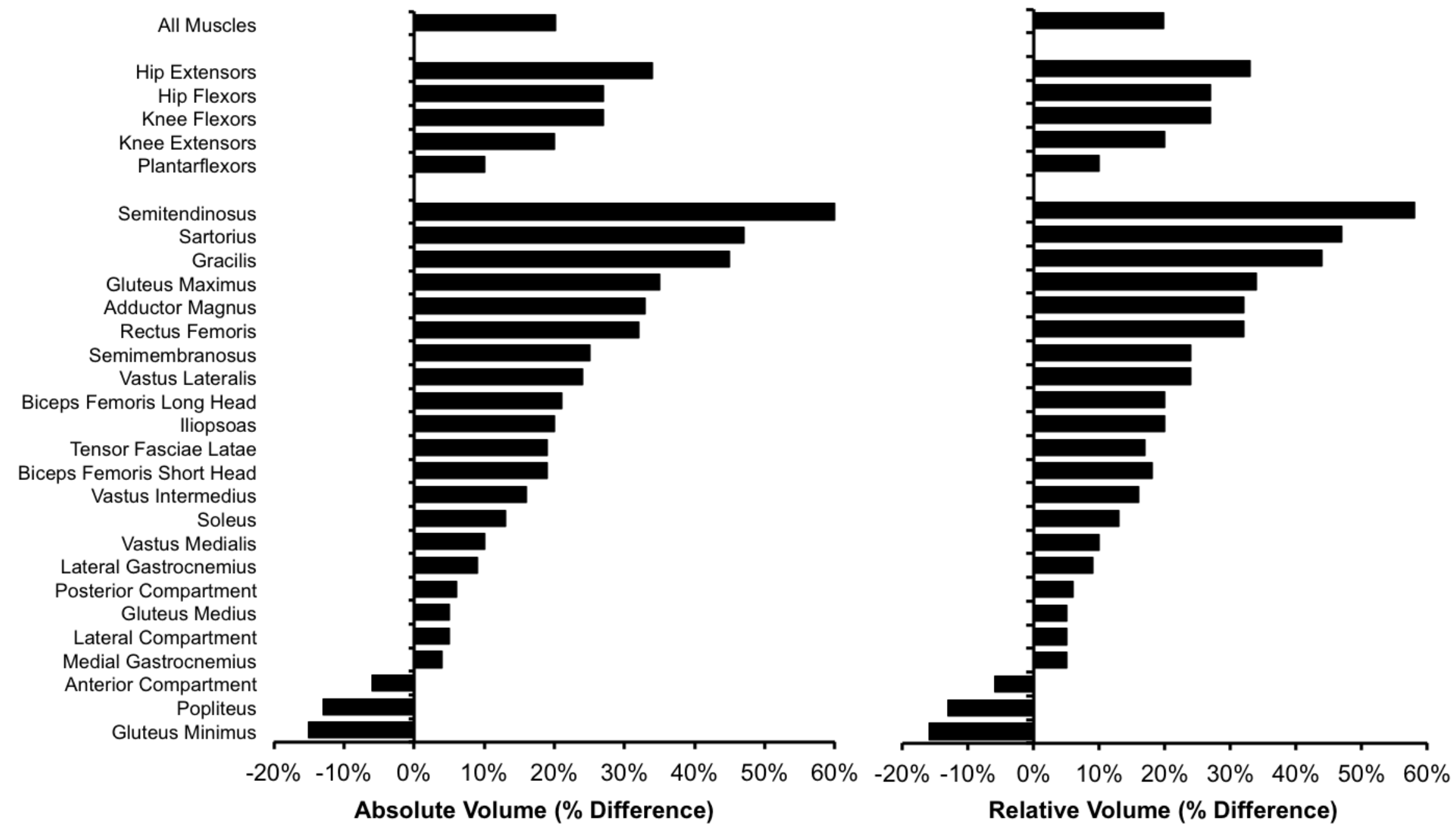


47 sub-elite sprinters vs. controls, and elite sprinters vs. sub-elite sprinters.

48

49

\begin{tabular}{|c|c|c|}
\hline & $\begin{array}{c}\text { Sub-Elite Sprinters }(\mathrm{n}=26) \\
\text { vs. } \\
\text { Controls }(\mathrm{n}=11)\end{array}$ & $\begin{array}{c}\text { Elite Sprinters }(\mathrm{n}=5) \\
\text { vs. } \\
\text { Sub-Elite Sprinters }(\mathrm{n}=26)\end{array}$ \\
\hline \multicolumn{3}{|l|}{ Absolute Muscle Volume $\left(\mathrm{cm}^{3}\right)$} \\
\hline Total Volume & $+20 \%$ & $+24 \%$ \\
\hline Functional Muscle Groups & $\begin{array}{l}\text { 4/5 muscle groups } \\
(+20-34 \% ; \text { not } \mathrm{PF})\end{array}$ & $\begin{array}{l}4 / 5 \text { muscle groups } \\
(+22-32 \% ; \text { not } \mathrm{PF})\end{array}$ \\
\hline Individual Muscles & 10 muscles $(+21-60 \%)$ & 8 muscles $(+22-57 \%)$ \\
\hline \multicolumn{3}{|c|}{ Relative Muscle Volume $\left(\mathrm{cm}^{3} \cdot \mathrm{kg}^{-1}\right)$} \\
\hline Total Volume & $+20 \%$ & - \\
\hline Functional Muscle Groups & $\begin{array}{l}\text { 4/5 muscle groups } \\
(+20-33 \% ; \text { not PF) }\end{array}$ & $\begin{array}{l}1 / 5 \text { muscle groups } \\
(+15 \% \mathrm{HE})\end{array}$ \\
\hline Individual Muscles & 12 muscles $(+16-58 \%)$ & 3 muscles $(+25-37 \%)$ \\
\hline
\end{tabular}

$\mathrm{PF}$, plantarflexors; HE, hip extensors. All listed differences were significant with $\mathrm{P} \leq 0.05$. 